\title{
Ectopic Pregnancy in Cases of Recurrent Implantation Failure and Cases of Recurrent Early Pregnancy Loss
}

\author{
Mohamed Elmahdy \\ Department of Obstetrics and Gynecology, Faculty of Medicine, Alexandria University, Alexandria, Egypt \\ Email: mahdy_moh@yahoo.com
}

How to cite this paper: Elmahdy, M. (2017) Ectopic Pregnancy in Cases of Recurrent Implantation Failure and Cases of Recurrent Early Pregnancy Loss. Open Journal of Obstetrics and Gynecology, 7, 250257.

https://doi.org/10.4236/ojog.2017.72027

Received: January 19, 2017

Accepted: February 21, 2017

Published: February 24, 2017

Copyright $\odot 2017$ by author and Scientific Research Publishing Inc. This work is licensed under the Creative Commons Attribution International License (CC BY 4.0).

http://creativecommons.org/licenses/by/4.0/

\begin{abstract}
Objectives: To calculate the incidence of ectopic pregnancy in cases with recurrent early pregnancy loss and cases of recurrent implantation failure. Methods and materials: This is a retrospective cohort study. 200 women were recruited from the infertility clinic at shat by maternity university hospital seeking fertility. 100 of them were with history of recurrent implantation failure (RIF) and 100 with history of recurrent pregnancy loss (RPL). Revisiting their hospital files for the history of ectopic pregnancy was done. Results: $8 \%$ of cases of RPL had history of ectopic pregnancy while only $6 \%$ of cases of RIF had the history. There was no significant difference between the two groups ( $\mathrm{p}$ $=0.579$ ). There was significantly higher incidence of ectopic pregnancy in both groups if compared with the general population ( $\mathrm{p}=0.0001$ and 0.043 ) in RPL and RIF consecutively. Conclusions: RPL and RIF may be considered as a risk factor for ectopic pregnancy.
\end{abstract}

\section{Keywords}

Ectopic Pregnancy, Recurrent Pregnancy Loss, Recurrent Implantation Failure

\section{Introduction}

Ectopic pregnancy (EP) refers to the blastocyst implantation outside the uterine cavity endometrium with over $92.5 \%$ implanting in the fallopian tube [1] [2]. The incidence of EP in the UK (11.1/1000 pregnancies) is similar to that in other countries, such as Norway (14.9/1000) and Australia (16.2/1000) [3].

Ectopic pregnancy may be tubal which is the dominant site [4], Cervical ectopic pregnancy (CEP) which is rare and represents only $0.15 \%$ of all EP [5], Ovarian ectopic pregnancy (OEP) is one of the rarest variants, and incidence is 
estimated to be $0.15 \%$ - $3 \%$ of all diagnosed OEP [6] [7].

$\mathrm{EP}$ is further common in women with previous history of pelvic inflammatory disease (PID) [8] and advancing maternal age [9]. Cigarette smoking is the major cause of one-third of all causes of EP [10]. The rate of tubal EP following in vitro fertilization (IVF) still remains higher (approximately $2 \%-5 \%$ ) than the rate of tubal EP with spontaneous pregnancy (1\% - 2\%) [9] [11]. Women with a previous history of EP also have an increased risk [12]. Some types of contraception, such as progestogen-only contraception and the intrauterine contraceptive device, are associated with an increased incidence of EP when there is contraceptive failure without necessarily increasing the absolute risk of EP [13].

Recurrent pregnancy loss (RPL) is defined as two or more failed clinical pregnancies [14]. It is estimated that fewer than $5 \%$ of women will experience two consecutive miscarriages, and only $1 \%$ experience three or more [15].

Recurrent implantation failure (RIF) was defined as failure to achieve clinical pregnancy after 3 or more embryo transfers with high quality embryos or the transfer of $\geq 10$ embryos in multiple transfers; exact numbers need to be determined [16].

Both of these previous two conditions have many similar risk factors and etiologies such as anatomic uterine factor [17], inherited [18] or acquired thrombophilia [19], cytogenetic abnormality [20], male factor [21] and infection such as endometritis [22].

The aim of this study is to evaluate the risk of ectopic pregnancy in cases with RIF and RPL.

\section{Materials and Methods}

1) Study design: retrospective cohort study.

2) Settings: the study was conducted at Elshat by maternity university hospital for cases of recurrent pregnancy loss and recurrent implantation failure attending the hospital from January 2016 till December 2016. This study has been approved by national research ethics committee and has been performed in accordance with the ethical standards as laid down in the 1964 Declaration of Helsinki and its later amendments or comparable ethical standards.

3) Participants: 200 woman attending the infertility clinic; first 100 woman of RPL attending this year and 100 women of RIF of 107 women attending in this year.

RPL was defined as two or more failed clinical pregnancies [14], while RIF was defined as failure to achieve clinical pregnancy after 3 or more embryo transfers with high quality embryos or the transfer of $\geq 10$ embryos in multiple transfers; exact numbers to be determined [16].

Inclusion criteria: women aged from 20 up to 37 year with past history of RPL or RIF.

Exclusion criteria: patients with mullerian anomalies, endometriosis and tubal factor infertility.

The files of the patients were revisited and analyzed to confirm inclusion cri- 
teria. Cases with past history of ectopic pregnancy were selected. Ectopic pregnancy was diagnosed by the appearance of extra uterine gestational sac by trans vaginal ultrasound scan with serum level of BHCG more than $1500 \mathrm{IU}$.

4) Statistical methodology:

Data were collected and entered to the computer using SPSS (Statistical Package for Social Science) program for statistical analysis (ver 21) [24]. Data were entered as numerical or categorical, as appropriate. When Kolmogorov-Smirnov test revealed no significance in the distribution of variables, parametric statistics was carried out, while in the not-normally distributed data the non-parametric statistics was carried out [25]. Data were described using minimum, maximum, median and inter-quartile range for not-normally distributed data. Categorical variables were described using frequency and percentage of total. Comparisons were carried out between two studied independent not-normally distributed subgroups using Mann-Whitney U test [26]. Chi-square test was used to test association between qualitative variables. Test for one proportion again population was carried using MedCalc Software version 14.

An alpha level was set to $5 \%$ with a significance level of $95 \%$, and a beta error accepted up to $20 \%$ with a power of study of $80 \%$.

\section{Results}

Patients with recurrent implantation failure were statistically significantly older in age (Mdn = 34.00) (IQR: $38.75-50.00)$ when compared with those with recurrent pregnancy loss $(\mathrm{Mdn}=30.00)(\mathrm{IQR}: 36.00-51.00)(Z=3.291, \mathrm{p}=0.001)$ (Table 1).

Table 1. Age (years).

\begin{tabular}{|c|c|c|}
\hline & \multicolumn{2}{|c|}{ Group } \\
\hline & $\begin{array}{l}\text { Recurrent ICSI failure } \\
\qquad(n=100)\end{array}$ & $\begin{array}{l}\text { Recurrent Pregnancy Loss } \\
\qquad(n=100)\end{array}$ \\
\hline Minimum & 20.00 & 16.00 \\
\hline Maximum & 43.00 & 46.00 \\
\hline Mean & 33.2100 & 30.6500 \\
\hline $95 \%$ CI for mean & $32.11-34.30$ & $29.44-31.85$ \\
\hline Std. Deviation & 5.52002 & 6.08422 \\
\hline Median & 34.0000 & 30.0000 \\
\hline Inter-quartile range & $38.75-50.00$ & $36.00-51.00$ \\
\hline KS test of normality & $\begin{array}{l}D=0.090 \\
\mathrm{p}=0.043^{*}\end{array}$ & $\begin{array}{l}D=0.092 \\
\mathrm{p}=0.036^{*}\end{array}$ \\
\hline Mann-Whitney U test & & $\begin{array}{l}291 \\
001^{*}\end{array}$ \\
\hline
\end{tabular}

KS: Kolmogorov-Smirnov; ${ }^{*}$ : Statistically significant $(\mathrm{p}<0.05)$; NS: Statistically not significant $(\mathrm{p}>0.05)$. 
There was no statistically significant difference in the incidence of ectopic pregnancy in patients with recurrent ICSI failure (6.0\%) when compared with those with recurrent pregnancy loss $(8.0 \%)\left(X^{2}=0.307, \mathrm{p}=0.579\right)$ (Table 2). When the incidence of each group compared with the general population prevalence reported by Khan et al. (2006) [1] (1\% - 2\%), patients with recurrent ICSI failure showed statistically significant higher incidence of ectopic pregnancy $(Z$ $=2.857, \mathrm{p}=0.0043)$; and also patient with recurrent pregnancy loss showed statistically significant higher incidence $(Z=4.286, \mathrm{p}<0.0001)$ (Table 3$)$.

\section{Discussion}

EP is estimated to be $1 \%-2 \%$ of all natural conceptions and the incidence increases following ART [27]. The prevalence of EP following ART ranges between $2.1 \%$ to $8.6 \%$ of all pregnancies and it can reach up to $11 \%$ in female patients with a history of tubal factor infertility [28]. Spontaneous HP was considered to be very rare with an incidence of 1 in 30,000 pregnancies. The incidence of HP has also increased following ART and it has been reported that it complicates about $0.8 \%$ of pregnancies following infertility treatment [29].

American pregnancy association considers risk factors for an ectopic pregnancy include several induced abortions and undergoing fertility treatment or using fertility medications [30].

Table 2. Incidence of ectopic pregnancy.

\begin{tabular}{lcc}
\hline & \multicolumn{3}{c}{ Group } \\
\cline { 2 - 3 } & $\begin{array}{c}\text { Recurrent ICSI failure } \\
(\mathbf{n}=100)\end{array}$ & $\begin{array}{c}\text { Recurrent Pregnancy Loss } \\
(\mathbf{n}=100)\end{array}$ \\
\hline Ectopic pregnancy & $94(94.0 \%)$ & $92(92.0 \%)$ \\
- Negative & $6(6.0 \%)$ & $8(8.0 \%)$ \\
- Positive & & $X^{2}=0.307$ \\
Pearson Chi-Square & $\mathrm{p}=0.579 \mathrm{NS}$ \\
\hline
\end{tabular}

NS: Statistically not significant $(\mathrm{p}>0.05)$.

Table 3. Comparison of incidence of ectopic pregnancy to the reference incidence in the general population (Khan et al., 2006) [1].

\begin{tabular}{|c|c|c|}
\hline & \multicolumn{2}{|c|}{ Group } \\
\hline & $\begin{array}{l}\text { Recurrent ICSI failure } \\
\qquad(\mathrm{n}=100)\end{array}$ & $\begin{array}{l}\text { Recurrent Pregnancy Loss } \\
\qquad(\mathrm{n}=100)\end{array}$ \\
\hline \multicolumn{3}{|l|}{ Ectopic pregnancy } \\
\hline - Negative & $94(94.0 \%)$ & $92(92.0 \%)$ \\
\hline - Positive & $6(6.0 \%)$ & $8(8.0 \%)$ \\
\hline - 95\% CI of observed percentage & $2.23 \%$ to $12.60 \%$ & $3.52 \%$ to $15.16 \%$ \\
\hline \multicolumn{3}{|c|}{ Prevalence in general population $=2 \%[23]$} \\
\hline & $Z=2.857$ & $Z=4.286$ \\
\hline & $\mathrm{p}=0.0043^{*}$ & $\mathrm{p}<0.0001^{\star}$ \\
\hline
\end{tabular}

*: Statistically significant $(\mathrm{p}<0.05)$. 
This study tried to find the incidence of ectopic pregnancy in cases of recurrent implantation failure and cases with recurrent early pregnancy loss.

The incidence of ectopic pregnancy was $6 \%$ in cases of recurrent implantation failure while heterotopic pregnancy was $1 \%$. This goes with what was found that IVF-ET is a major risk for the development of EP and the incidence is greater by 2 - 3 folds than that seen in the general population. IVF may also result in a heterotopic pregnancy (HP), which is an EP together with a viable intrauterine pregnancy [31]. Ma Nz et al. found that in IVF cycles the incidence of ectopic pregnancy increased significantly in patients with thin endometrium than those with endometrium less than $8 \mathrm{~mm}$ [32]. Meta-analysis by Muller suggests that EP rate is similar following fresh blastocyst and cleavage ETs, but is significantly reduced after frozen compared with fresh ET [33]. The reason for the increased incidence of tubal EP by IVF is unclear. The technique of embryo transfer is a potential cause but there is little evidence to support this. The risk of tubal EP has also been reported to increase with the number of embryos that are transferred during IVF treatment [34]. A possible mechanism for this finding may be postulated to the effect of high estradiol concentration. Elevated estradiol leads to alteration in the normal physiologic function of the fallopian tube, increasing the likelihood for extra uterine implantation [35].

Stimulation protocols were found to affect the incidence of ectopic pregnancy after ICSI-ET. Ectopic pregnancy was more frequent with GnRH antagonist (2.4\%) cycles than with GnRH agonist flare (2.1\%) or luteal GnRH agonist (1.6\%) cycles. This finding suggests a role for extra pituitary GnRH on the tubal and uterine environment during ovarian hyperstimulation treatment for IVF [36].

Our results match what was found by Ji Hyun that the risk factors for heterotopic pregnancy include a history of ectopic pregnancy (OR 7.191 [1.591 32.513], $\mathrm{p}=0.010$ ), abortion (OR 3.948 [1.574 - 9.902], $\mathrm{p}=0.003$ ), and ovarian hyperstimulation syndrome (OHSS) (OR 10.773 [2.415 - 48.060], $\mathrm{p}=0.002$ ). In patients undergoing IVF-ET, history of ectopic pregnancy, abortion, and OHSS may be risk factors for HP as compared to the control group of other IVF patients [37]. A surprising observation was found in the case of heterotopic pregnancy, it was found that the extra uterine sac was pulsating while the two intra uterine sacs were missed. This may reflect the altered endometrial milieu that is hostile for implantation and may be one of the possible mechanism for RPL and RIF.

Our study also, showed $8 \%$ incidence of ectopic pregnancy in cases of recurrent early pregnancy loss. This represents about four fold increase in the incidence than the general population. This finding may reflect the hostile effect of the endometrium on both ectopic pregnancy occurrence and RPL.

The limitation of this study were the difference between patients according to ovarian stimulation protocol, the difference according to day of ET either day 3 or day 5 and the non homogeneity as regards the number of embryos transferred. 


\section{Conclusion}

In conclusion, RIF and RPL may be considered as a risk factor for ectopic pregnancy. Endometrium plays an important role in RPL.

\section{Acknowledgements}

To staff members of infertility clinic, Alexandria University Hospital.

\section{Disclosure Statement}

There is nothing to disclose.

\section{References}

[1] Khan, K.S., Wojdyla, D., Say, L., Gulmezoglu, A.M. and Van Look, P.F. (2006) WHO Analysis of Causes of Maternal Death: A Systematic Review. Lancet, 367, 1066-1074. https://doi.org/10.1016/S0140-6736(06)68397-9

[2] Shaw, J.L., Dey, S.K., Critchley, H.O. and Horne, A.W. (2010) Current Knowledge of the Aetiology of Human Tubal Ectopic Pregnancy. Human Reproduction Update, 16, 432-441. https://doi.org/10.1093/humupd/dmp057

[3] Bakken, I.J. and Skjeldestad, F.E. (2003) Incidence and Treatment of Extra Uterine Pregnancies in Norway 1990-2001. Tidsskrift for Den Norske Laegeforening, 123, 3016-3020.

[4] Condous, G. (2004) The Management of Early Pregnancy Complications. Best Practice \& Research Clinical Obstetrics \& Gynaecology, 18, 37-57. https://doi.org/10.1016/j.bpobgyn.2003.09.011

[5] Webb, E.M., Green, G.E. and Scoutt, L.M. (2004) Adnexal Mass with Pelvic Pain. Radiologic Clinics of North America, 42, 329-348. https://doi.org/10.1016/j.rcl.2003.12.006

[6] Odejinmi, F., Rizzuto, M.I., MacRae, R., Olowu, O. and Hussain, M. (2009) Diagnosis and Laparoscopic Management of 12 Consecutive Cases of Ovarian Pregnancy and Review of Literature. Journal of Minimally Invasive Gynecology, 16, 354-359. https://doi.org/10.1016/j.jmig.2009.01.002

[7] Gon, S. (2011) Two Cases of Primary Ectopic Ovarian Pregnancy. Online Journal of Health \& Allied Sciences, 10, 1-2.

[8] Madhuri, P. (2009) Ectopic Pregnancy after Infertility Treatment. Journal of Human Reproductive Sciences, 5, 154-165.

[9] Farquhar, C.M. (2005) Ectopic Pregnancy. Lancet, 366, 583-591. https://doi.org/10.1016/S0140-6736(05)67103-6

[10] Bouyer, J., Coste, J. and Shojaei, T. (2003) Risk Factors for Ectopic Pregnancy: A Comprehensive Analysis Based on a Large Case-Control, Population-Based Study in France. American Journal of Epidemiology, 157, 185-194. https://doi.org/10.1093/aje/kwf190

[11] Strandell, A., Thorbum, J. and Hamberger, L. (1999) Risk Factors for Ectopic Pregnancy in Assisted Reproduction. Fertility and Sterility, 71, 282-286. https://doi.org/10.1016/S0015-0282(98)00441-5

[12] Madhuri, P. (2012) Ectopic Pregnancy after Infertility Treatment. Journal of Human Reproductive Sciences, 5, 154-165. https://doi.org/10.4103/0974-1208.101011

[13] Furlong, L.A. (2002) Ectopic Pregnancy Risk When Contraception Fails: A Review. Journal of Reproductive Medicine, 47, 881-885. 
[14] Van den Boogaard, E., Kaandorp, S.P., Franssen, M.T., Mol, B.W., Leschot, N.J., et al. (2010) Consecutive or Non-Consecutive Recurrent Miscarriage: Is There Any Difference in Carrier Status? Human Reproduction, 25, 1411-1414. https://doi.org/10.1093/humrep/deq089

[15] Stirrat, G.M. (1990) Recurrent Miscarriage. Lancet, 336, 673-675. https://doi.org/10.1016/0140-6736(90)92159-F

[16] Thomhill, A.R., de Die-Smulders, C.E., Geraedts, J.P., Harper, J.C., Harton, G.L., Lavery, S.A., et al. (2005) ESHRE PGD Consortium' Best Practice Guide Lines for Clinical Preimplantation Genetic Screening (PGD). Human Reproduction, 20, 3548. https://doi.org/10.1093/humrep/deh579

[17] Rai, R. and Regan, L. (2006) Recurrent Miscarriage. Lancet, 368, 601-611. https://doi.org/10.1016/S0140-6736(06)69204-0

[18] De Jong, P.G., Goddijn, M. and Middwldorp, S. (2011) Testing for Inherited Thrombophilia in Recurrent Miscarriage. Seminars in Reproductive Medicine, 29, 540-545. https://doi.org/10.1055/s-0031-1293207

[19] ACOG (2011) Antiphospholipid Syndrome. ACOG Practice Bulletin No. 118.

[20] Philipp, T., Philipp, K., Reiner, A., Beer, F. and Kalousek, D.K. (2003) Embroscopic and Cytogenetic Analysis of 233 Missed Abortions: Factors Involved in the Pathogenesis of Developmental Defects of Early Failed Pregnancies. Human Reproduction, 18, 1724-1732. https://doi.org/10.1093/humrep/deg309

[21] Carrell, D.T., Liu, L., Peterson, C.M., Jones, K.P., Hatasaka, H.H., Erickson, L. and Campbell, B. (2003) Sperm DNA Fragmentation Is Increased in Couples with Unexplained Recurrent Pregnancy Loss. Archives of Andrology, 49, 49-55. https://doi.org/10.1080/01485010290099390

[22] Penta, M., Lukic, A., Conte, M.P., Chiarini, F., Fioriti, D., et al. (2003) Infectious Agents in Tissues from Spontaneous Abortions in the First Trimester of Pregnancy. New Microbiologica, 26, 329-337.

[23] Mehta, T.S., Levine, D. and Beckwith, B. (1997) Treatment of Ectopic Pregnancy: Is a Human Chorionic Gonadotropin Level of 2,000 mIU/mL a Reasonable Threshold? Radiology, 205, 569-573. https://doi.org/10.1148/radiology.205.2.9356647

[24] IBM Corp Released 2012. IBM SPSS Statistics for Windows. Version 21.0. IBM Corp, Armonk.

[25] Field, A. (2006) Discovering Statistics Using SPSS. 2nd Edition, Sage, London.

[26] MedCalc Statistical Software Version 14.8.1 (2014) MedCalc Software Bvba, Ostend. http://www.medcalc.org

[27] Jurkovic, D. and Wilkinson, H. (2011) Diagnosis and Management of Ectopic Pregnancy. BMJ, 342, d3397. https://doi.org/10.1136/bmj.d3397

[28] Clayton, H.B., Schieve, L.A., Peterson, H.B., Jamieson, D.J., Reynolds, M.A. and Wright, V.C. (2006) Ectopic Pregnancy Risk with Assisted Reproductive Technology Procedures. Obstetrics \& Gynecology, 107, 595-604. https://doi.org/10.1097/01.AOG.0000196503.78126.62

[29] Wang, L.L., Chen, X., Ye, D.S., Liu, Y.D., He, Y.X., Guo, W., et al. (2014) Misdiagnosis and Delayed Diagnosis for Ectopic and Heterotopic Pregnancies after in Vitro Fertilization and Embryo Transfer. Journal of Huazhong University of Science and Technology, 34, 103-107. https://doi.org/10.1007/s11596-014-1239-7

[30] Wang, L., Qiao, J., Li, R., Zhen, X. and Liu, Z. (2010) Role of Endometrial Blood Flow Assessment with Color Doppler Energy in Predicting Pregnancy Outcome of IVF-ET Cycles. Reproductive Biology and Endocrinology, 8, 122. https://doi.org/10.1186/1477-7827-8-122 
[31] Chang, H.J. and Suh, C.S. (2010) Ectopic Pregnancy after Assisted Reproductive Technology: What Are the Risk Factors? Current Opinion in Obstetrics \& Gynecology, 22, 202-207. https://doi.org/10.1097/GCO.0b013e32833848fd

[32] Ma, N.Z., Chen, L., Dai, W., Bu, Z.Q., Hu, L.L. and Sun, Y.P. (2017) Influence of Endometrial Thickness on Treatment Outcomes Following in Vitro Fertilization/ Intracytoplasmic Sperm Injection. Reproductive Biology and Endocrinology, 15, 5. https://doi.org/10.1186/s12958-016-0222-5

[33] Muller, V., Makhmadalieva, M. and Kogan, I. (2016) Ectopic Pregnancy Following in Vitro Fertilization: Meta-Analysis and Single-Center Experience during 6 Years. Gynecological Endocrinology, 32, 69-74. https://doi.org/10.1080/09513590.2016.1232550

[34] Weigert, M., Gruber, D., Pernicka, E., Bauer, P. and Feichtinger, W. (2009) Previous Tubal Ectopic Pregnancy Raises the Incidence of Repeated Ectopic Pregnancies in in Vitro Fertilization-Embryo Transfer Patients. Journal of Assisted Reproduction and Genetics, 26, 13-17. https://doi.org/10.1007/s10815-008-9278-2

[35] Shao, R., Feng, Y., Zou, S., Weijdegård, B., Wu, G., Brännström, M. and Billig, H. (2012) The Role of Estrogen in the Pathophysiology of Tubal Ectopic Pregnancy. American Journal of Translational Research, 4, 269-278.

[36] Londra, L., Moreau, C., Strobino, D., Bhasin, A. and Zhao, Y. (2016) Is the Type of Gonadotropin-Releasing Hormone Suppression Protocol for Ovarian Hyperstimulation Associated with Ectopic Pregnancy in Fresh Autologous Cycles for in Vitro Fertilization? Fertility and Sterility, 106, 666-672. https://doi.org/10.1016/j.fertnstert.2016.05.019

[37] Jeon, J., Hwang, Y. and Shin, I. (2016) The Risk Factors and Pregnancy Outcomes of 48 Cases of Heterotopic Pregnancy from a Single Center. Journal of Korean Medical Science, 31, 1094-1099. https://doi.org/10.3346/jkms.2016.31.7.1094

Submit or recommend next manuscript to SCIRP and we will provide best service for you:

Accepting pre-submission inquiries through Email, Facebook, LinkedIn, Twitter, etc. A wide selection of journals (inclusive of 9 subjects, more than 200 journals)

Providing 24-hour high-quality service

User-friendly online submission system

Fair and swift peer-review system

Efficient typesetting and proofreading procedure

Display of the result of downloads and visits, as well as the number of cited articles

Maximum dissemination of your research work

Submit your manuscript at: http://papersubmission.scirp.org/

Or contact ojog@scirp.org 